Supporting Information Available in Web Edition

\title{
HCl droplets induced bunched steps on ice crystal surfaces under atmospheric-concentration $\mathrm{HCl}$ gas
}

\author{
Ken Nagashima*, Ken-ichiro Murata, Gen Sazaki
}

Institute of Low Temperature Science, Hokkaido University, N19-W8, Kita-ku, Sapporo 0600819, Japan

\section{Contents}

Section S1. Behaviors of droplets and thin layers under middle $P_{\mathrm{HCl}}$ in the temperature range from -5 to $0{ }^{\circ} \mathrm{C}$

Section S2. A plausible cause for the shrinkage and subsequent disappearance of a droplet on a basal face with decreasing temperature under low and middle $P_{\mathrm{HCl}}$

Section S3. Behaviors of droplets under low $P_{\mathrm{HCl}}$ at temperatures below $-10{ }^{\circ} \mathrm{C}$

References

* To whom correspondence should be addressed. E-mail: nagasima@lowtem.hokudai.ac.jp 
Section S1. Behaviors of droplets and thin layers under middle $P_{\mathrm{HCl}}$ in the temperature range from -5 to $0{ }^{\circ} \mathrm{C}$

Under middle $P_{\mathrm{HCl}}$, we also investigated ice basal faces at temperatures near the melting point (from -5 to $0{ }^{\circ} \mathrm{C}$ ) by LCM-DIM (Figure S1 and S2). Then, we obtained the results similar to those under low $P_{\mathrm{HCl}}$ (Figure 3 and 4).

As shown in Figure S1, with increasing temperature, droplets (white arrows in Figure S1D) and thin layers (black arrows in Figure S1B and C) appeared. In contrast, with decreasing temperature, the droplet and thin layers spontaneously disappeared (Figure S1H-L) at almost the same temperatures at which they appeared. We observed the coalescence of the droplets (white arrows in Figure S1G and H) and thin layers (black arrows in Figure S1E and F), and a wetting transition from a thin layer to a droplet (black arrowheads in Figure S1C-E).

In addition, as shown in Figure S2, one large droplet often appeared on ice basal faces, although the large droplet disappeared with decreasing temperature. The phenomena shown in Figure S1 and S2 occurred at almost the same frequency.

From Figure S1 and S2, we conclude that the phenomena similar to those under low $P_{\mathrm{HCl}}$ (Figure 3 and 4 ) occurred also under middle $P_{\mathrm{HCl}}$.

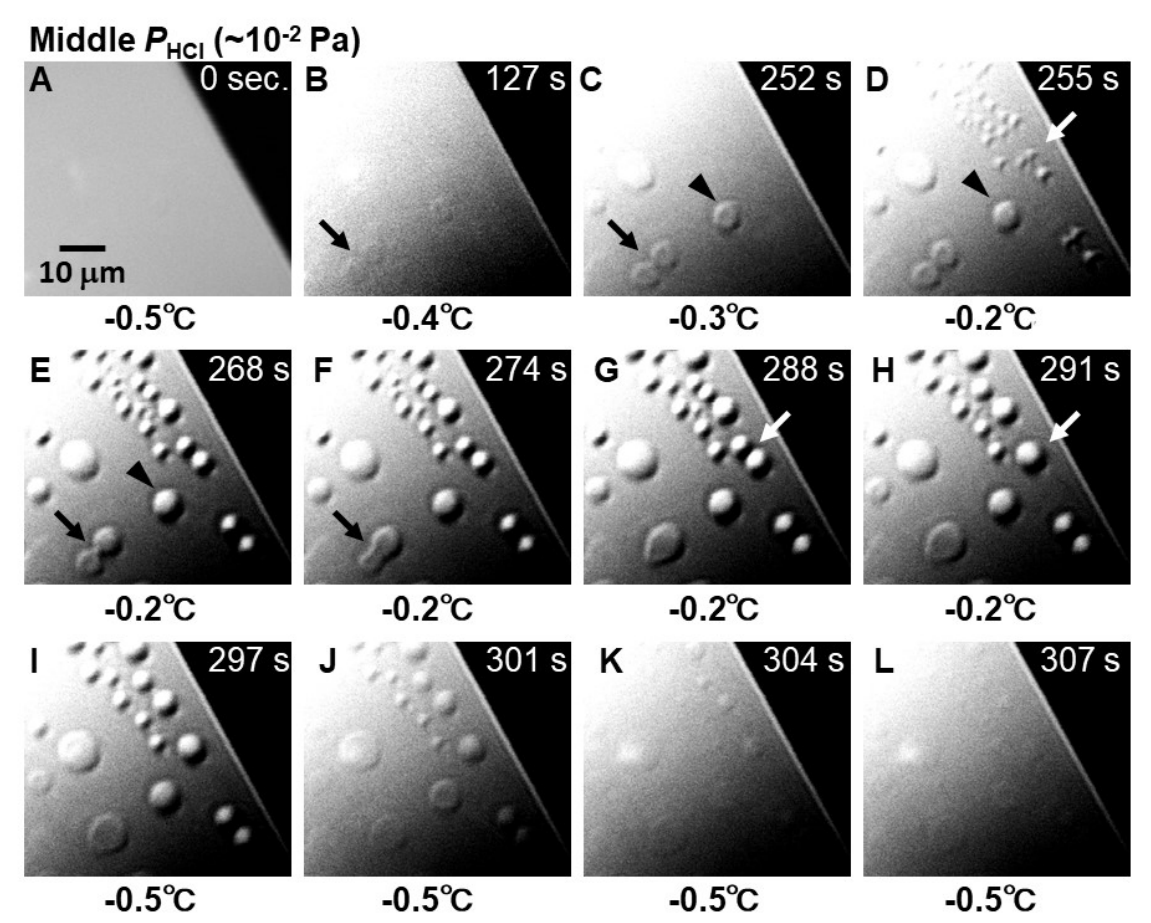

Figure S1. Behaviors of an ice basal face under middle $P_{\mathrm{HCl}}\left(10^{-2} \mathrm{~Pa}\right)$ at temperatures from 0.5 to $-0.2{ }^{\circ} \mathrm{C}$. $P_{\mathrm{H} 2 \mathrm{O}}$ was kept constant at $660 \mathrm{~Pa}$, and $P_{\mathrm{H} 2 \mathrm{O}}{ }^{\text {eq }}$ ranged from $610 \mathrm{~Pa}\left(-0.5^{\circ} \mathrm{C}\right)$ to $600 \mathrm{~Pa}\left(-0.2{ }^{\circ} \mathrm{C}\right)$. (A-H) A series of LCM-DIM images shows the appearance of droplets and 
thin layers on the ice surface with increasing temperature. (H-L) The disappearance of the droplets and thin layers with decreasing temperature. White and black arrows present droplets and thin layers, respectively. Black arrowheads indicate the transition from a thin layer to a droplet. The phenomena shown in this figure correspond to those under low $P_{\mathrm{HCl}}$ in Figure 3 in the main text.
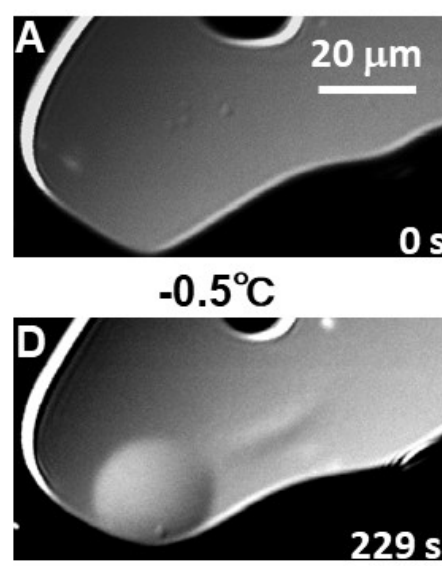

$-0.5^{\circ} \mathrm{C}$

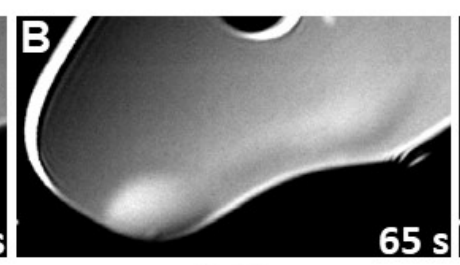

$-0.4^{\circ} \mathrm{C}$

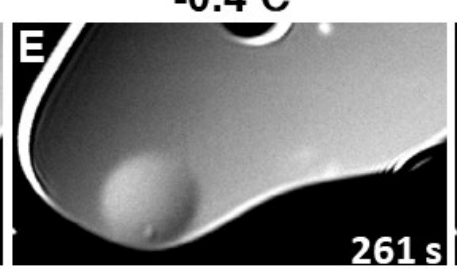

$-0.6^{\circ} \mathrm{C}$

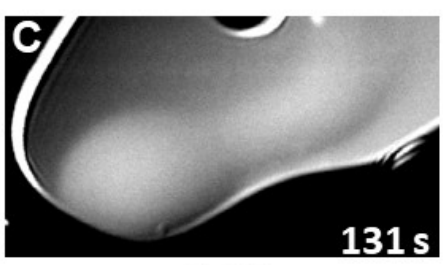

$-0.3^{\circ} \mathrm{C}$

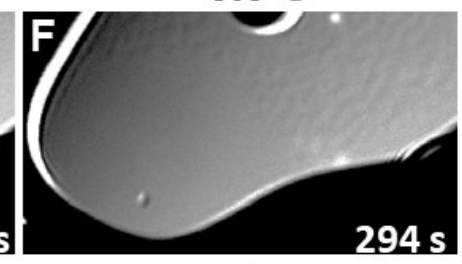

$-1.6^{\circ} \mathrm{C}$

Figure S2. A different behavior of an ice basal face under middle $P_{\mathrm{HCl}}\left(10^{-2} \mathrm{~Pa}\right)$ at temperatures from -1.6 to $-0.3{ }^{\circ} \mathrm{C}$. $P_{\mathrm{H} 2 \mathrm{O}}$ was kept constant at $610 \mathrm{~Pa}$, and $P_{\mathrm{H} 2 \mathrm{O}}{ }^{\mathrm{eq}}$ ranged from $540 \mathrm{~Pa}\left(-1.6^{\circ} \mathrm{C}\right)$ to $600 \mathrm{~Pa}\left(-0.3^{\circ} \mathrm{C}\right)$. (A-C) A series of LCM-DIM images demonstrates that with increasing temperature, one large droplet appeared on the ice surface. As time elapsed, the shape of the droplet was gradually changed (B and C), and finally became spherical (D). (C-F) With decreasing temperature, the large droplet disappeared spontaneously. The appearance of the large droplet (shown in this figure) occurred as often as the appearance of many small droplets shown in Figure $\mathrm{S} 1$. The phenomena shown in this figure correspond to those under low $P_{\mathrm{HCl}}$ in Figure 4 in the main text. 


\section{Section S2. A plausible cause for the shrinkage and subsequent disappearance of a droplet}

on a basal face with decreasing temperature under low and middle $\boldsymbol{P}_{\mathrm{HCl}}$

In the presence of $\mathrm{HNO}_{3}$ gas of $10^{-4}-10^{-2} \mathrm{~Pa}$, we previously reported that with decreasing temperature, a droplet formed on an ice basal face gradually shrank and finally disappeared spontaneously. ${ }^{1}$ During this process, we measured the volume of the droplet as a function of temperature. When we assumed that the droplet (an $\mathrm{HNO}_{3}$ aqueous solution) and ice were in equilibrium, we found that the temperature change in $\mathrm{HNO}_{3}$ concentration (calculated from the volume change) fully coincided with a binary phase diagram of water and $\mathrm{HNO}_{3}{ }^{2}$ Therefore, we concluded that the droplet was an $\mathrm{HNO}_{3}$ aqueous solution that was in equilibrium with an ice crystal.

In this paper, we adopt the same concept. Then we explain the shrinkage and subsequent disappearance of a droplet with decreasing temperature in the presence of $\mathrm{HCl}$ gas, as follows. Figure S3A shows a binary phase diagram of a water- $\mathrm{HCl}$ system. ${ }^{3}$ First, we assume that a droplet of an $\mathrm{HCl}$ solution and an ice crystal are in equilibrium at point $\mathrm{X}_{1}$ (shown schematically in Figure S3B). When we reduce the temperature from $T_{1}$ to $T_{2}$, the $\mathrm{HCl}$ droplet becomes supercooled at point $\mathrm{X}^{\prime}$. Then, water freezes out of the $\mathrm{HCl}$ droplet (thereby fueling the growth of the underlying ice crystal), resulting in an increase in $\mathrm{HCl}$ concentration. The freezing of water out of the $\mathrm{HCl}$ droplet stops when the concentration reached $C_{2}$, because the $\mathrm{HCl}$ droplet and the ice crystal are now in equilibrium at point $\mathrm{X}_{2}$. By repeating the same process, the $\mathrm{HCl}$ droplet becomes smaller with decreasing temperature. Then finally, the size of the $\mathrm{HCl}$ droplet becomes smaller than the resolution limit of LCM-DIM $(\sim 1 \mu \mathrm{m}):$ the $\mathrm{HCl}$ droplet disappears from an LCM-DIM image. When $P_{\mathrm{HCl}}$ is lower than an equilibrium $\mathrm{HCl}$ pressure of the $\mathrm{HCl}$ droplet, $\mathrm{HCl}$ evaporates from the $\mathrm{HCl}$ droplet, resulting in the acceleration of the shrinkage of the $\mathrm{HCl}$ droplet. 

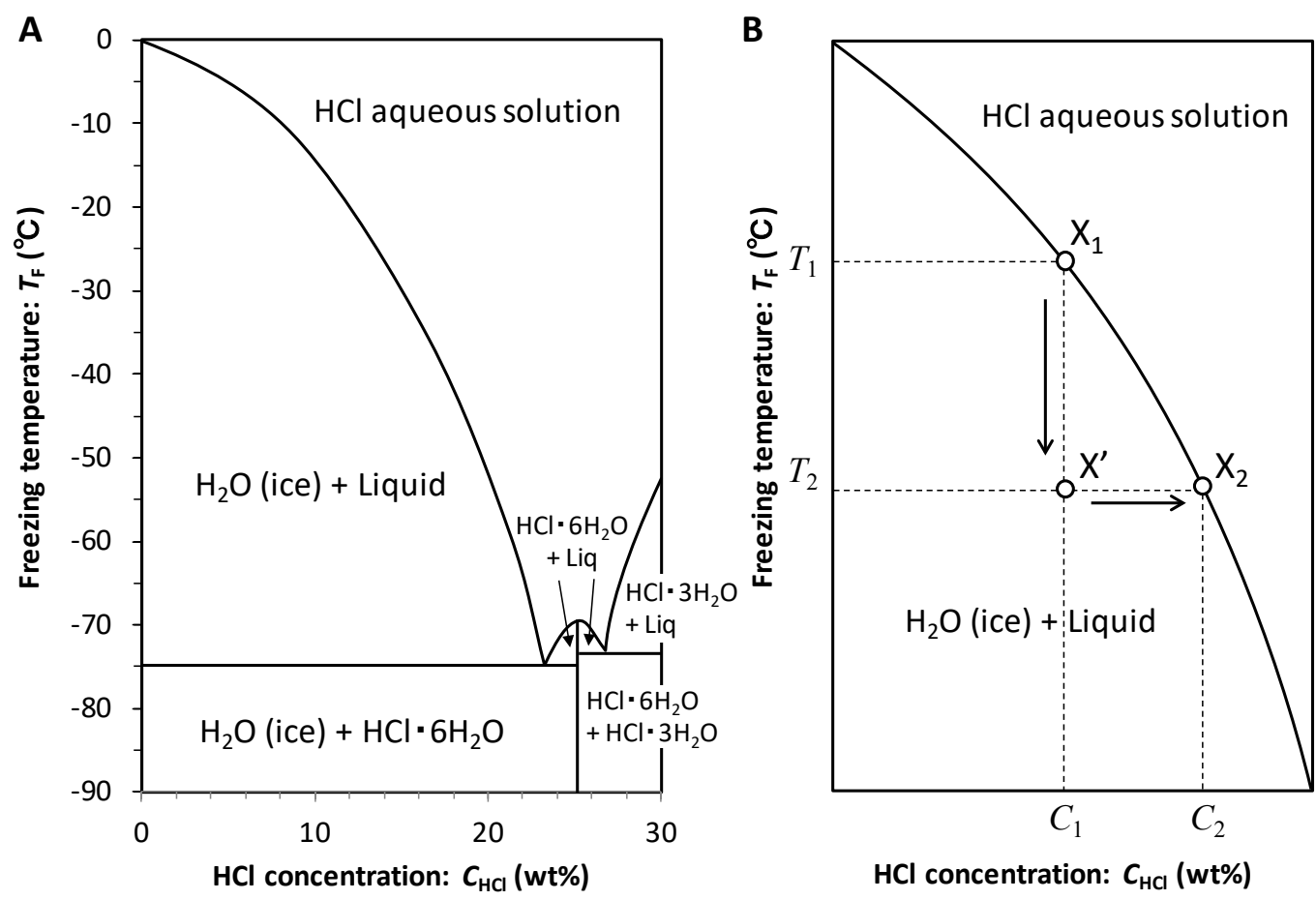

Figure S3. A phase diagram of a water-HCl binary system(A), ${ }^{3}$ and a schematic illustration for the explanation of the concentration change with temperature (B). 


\section{Section S3. Behaviors of droplets under low $\boldsymbol{P}_{\mathrm{HCl}}$ at temperatures below $-10{ }^{\circ} \mathrm{C}$}

Under low $P_{\mathrm{HCl}}$, we also investigated ice basal faces by LCM-DIM at temperatures below $10^{\circ} \mathrm{C}$ (Figure S4-6). Then, we obtained the results similar to those under middle $P_{\mathrm{HCl}}$ (Figure 5-7)

As shown in Figure S4, droplets appeared with decreasing temperature below $-10^{\circ} \mathrm{C}$. When we observed ice crystal surfaces below $-10^{\circ} \mathrm{C}$, the ice surfaces usually had been already covered with bunched steps, as shown in Figures S5 and 6. Hence, the observation of the formation of droplets on a flat ice surface is relatively difficult. Therefore, with respect to the disappearance of droplets with increasing temperature, we have no image. However, as we will explain later in Figure S6, we could observe the dissolution of bunched steps with increasing temperature. Therefore, we believe that we have evidence enough for the disappearance of droplets with increasing temperature.

In addition, as shown in Figure S5, droplets appeared at temperatures below $-10{ }^{\circ} \mathrm{C}$ (black arrows in Figure S5A) pinned the lateral growth of steps and then formed bunched steps (black arrowheads in Figure S5B). The differential interference contrast indicates that some droplets (white arrows in Figure S5A) were embedded in the ice crystal. After the droplets were embedded in the ice crystal, the growth of the ice crystal was suppressed at the positions just above the embedded droplets, as explained in detail in our previous study. ${ }^{4}$ Hence, hollows were formed just above the embedded droplets (white arrowheads in Figure S5B), although such details were not explained in the main text.

Figure S6A and B shows bunched steps formed on a basal face at temperatures below $-10{ }^{\circ} \mathrm{C}$. During 5 min., the bunched steps did not grow significantly. In contrast, as shown in Figure $\mathrm{S} 6 \mathrm{C}$ and $\mathrm{D}$, after the temperature was increased at $0 \mathrm{~min}$ from -13.6 to $-11.6{ }^{\circ} \mathrm{C}$, the pinning of the bunched steps was dissolved gradually, and the bunched steps grew laterally (white arrowheads in Figure S6C-D).

From Figure S4-6, we conclude that the phenomena similar to those under middle $P_{\mathrm{HCl}}$ (Figure 5-7) occurred also under low $P_{\mathrm{HCl}}$. 


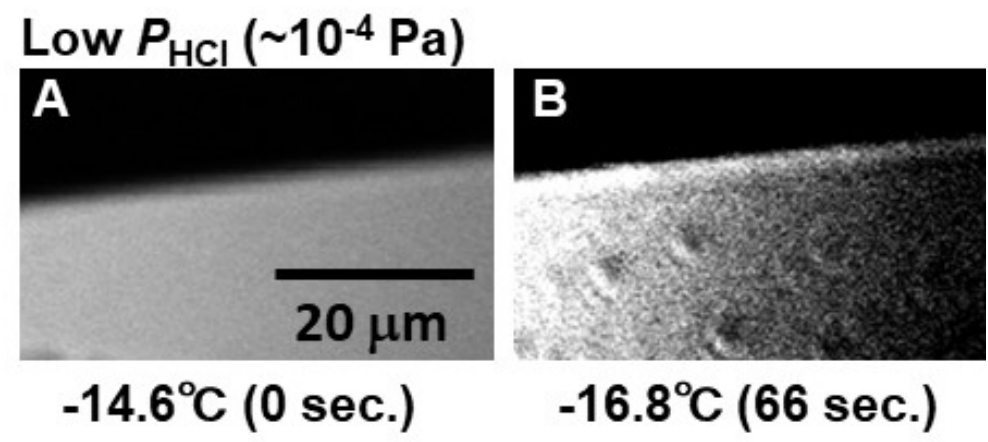

Figure S4. LCM-DIM images of an ice basal face under low $P_{\mathrm{HCl}}\left(\sim 10^{-4} \mathrm{~Pa}\right)$, showing the appearance of droplets on the ice surface with decreasing temperature from -14.6 to $-16.8{ }^{\circ} \mathrm{C}$. $P_{\mathrm{H} 2 \mathrm{O}}$ was kept constant at $400 \mathrm{~Pa}$, and $P_{\mathrm{H} 2 \mathrm{O}}{ }^{\mathrm{eq}}$ was changed from $170 \mathrm{~Pa}\left(-14.6{ }^{\circ} \mathrm{C}\right)$ to $140 \mathrm{~Pa}(-$ $16.8^{\circ} \mathrm{C}$ ). The phenomenon shown in this figure corresponds to that under middle $P_{\mathrm{HCl}}$ in Figure $5 \mathrm{~A}$ in the main text.
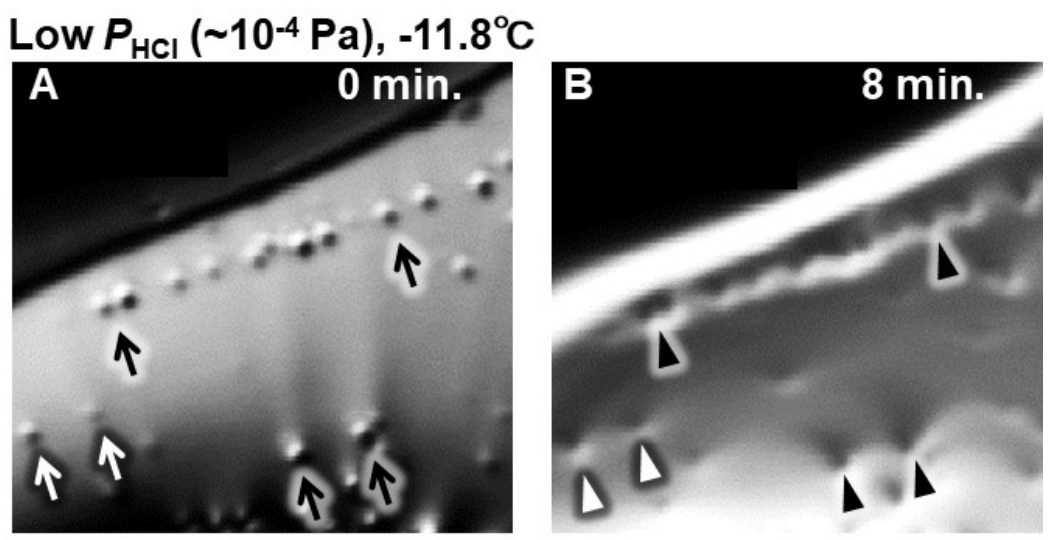

Figure S5. LCM-DIM images of an ice basal face under low $P_{\mathrm{HCl}}\left(\sim 10^{-4} \mathrm{~Pa}\right)$ at a constant temperature of $-11.8^{\circ} \mathrm{C}\left(P_{\mathrm{H} 2 \mathrm{O}} \mathrm{eq}=230 \mathrm{~Pa}\right)$. Images taken under supersaturated $P_{\mathrm{H} 2 \mathrm{O}}\left(P_{\mathrm{H} 2 \mathrm{O}}=\right.$ $240 \mathrm{~Pa}$ ) indicate that droplets on the ice surface (black arrows) pinned the lateral growth of steps and subsequently formed bunched steps (black arrowheads), and also that droplets (white arrows) were embedded in the ice surface showing hollows (white arrowheads) just above the embedded droplets. The phenomena shown in this figure correspond to those under middle $P_{\mathrm{HCl}}$ in Figure 6 in the main text. 


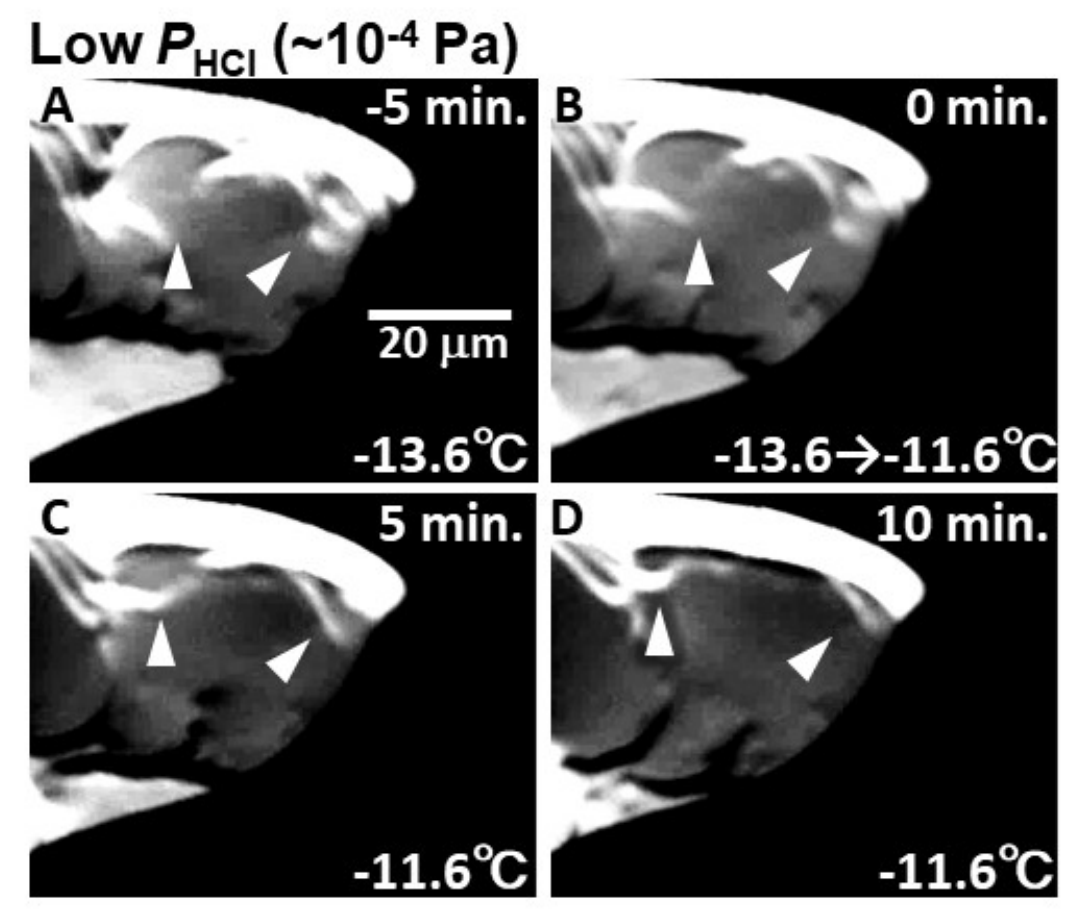

Figure S6. Disappearance of bunched steps on an ice basal face under low $P_{\mathrm{HCl}}\left(\sim 10^{-4} \mathrm{~Pa}\right)$ with increasing temperature. $P_{\mathrm{H} 2 \mathrm{O}}$ was kept constant at $540 \mathrm{~Pa}$ throughout the observation. (A and B) LCM-DIM images of the basal face at $-13.6{ }^{\circ} \mathrm{C}\left(P_{\mathrm{H} 2 \mathrm{O}}{ }^{\mathrm{eq}}=190 \mathrm{~Pa}\right)$. Bunched steps existing on the basal face did not show significant lateral growth during 5 min. (C-D) LCM-DIM images show a time-course of the basal face at $-11.6^{\circ} \mathrm{C}\left(P_{\mathrm{H} 2 \mathrm{O}}{ }^{\mathrm{eq}}=230 \mathrm{~Pa}\right)$. Temperature was started to increase at $0 \mathrm{~s}$ and reached at $-11.6^{\circ} \mathrm{C}$ within $1 \mathrm{~min}$. As time elapsed, the pinning of the bunched steps was gradually dissolved, and hence the bunched steps grew in the lateral direction significantly (white arrowheads). The phenomena shown in this figure correspond to those in Figure 7 in the main text. 


\section{References}

(1) Nagashima, K.; Maurais, J.; Murata, K.; Furukawa, Y.; Ayotte, P.; Sazaki, G. Appearance and Disappearance of Quasi-Liquid Layers on Ice Crystals in the Presence of Nitric Acid Gas. Crystals 2020, 10 (2), 72.

(2) Beyer, K. D.; Hansen, A. R. Phase Diagram of the Nitric Acid/Water System: Implications for Polar Stratospheric Clouds. J. Phys. Chem. A 2002, 106 (43), 10275-10284.

(3) Pickering, S. U. Die Hydrate Der Chlorwasserstoffsäure. Berichte der Dtsch. Chem. Gesellschaft 1893, 26 (1), 277-284.

(4) Nagashima, K.; Sazaki, G.; Hama, T.; Murata, K.; Furukawa, Y. Uptake Mechanism of Atmospheric Hydrogen Chloride Gas in Ice Crystals via Hydrochloric Acid Droplets. Cryst. Growth Des. 2018, 18 (7), 4117-4122. 